\title{
Synthesis and Structure of $m$-Terphenyl Thio-, Seleno-, and Telluroethers
}

\author{
Uzma I. Zakai, ${ }^{\dagger}$ Anna Błoch-Mechkour, ${ }^{\star}$ Neil E. Jacobsen,${ }^{\dagger}$ Leif Abrell,${ }^{\dagger}$ Guangxin Lin, ${ }^{\dagger}$ \\ Gary S. Nichol, ${ }^{\dagger}$ Thomas Bally,** and Richard S. Glass* ${ }^{*}$ \\ ${ }^{\dagger}$ Department of Chemistry and Biochemistry, The University of Arizona, Tucson, Arizona 85721, \\ United States, and Department of Chemistry, University of Fribourg, CH-1700 Fribourg, Switzerland
}

rglass@u.arizona.edu; thomas.bally@unifr.ch

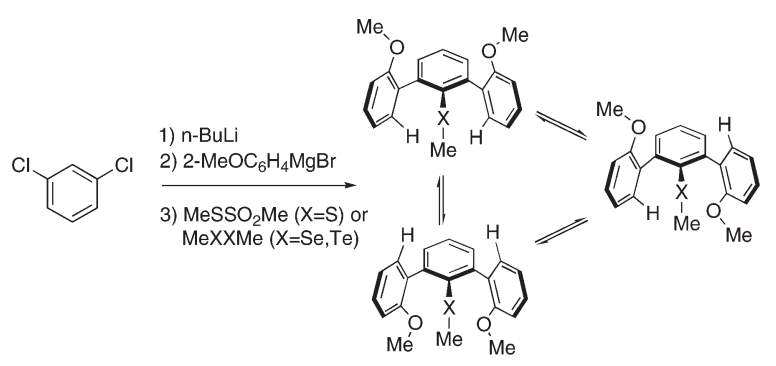

Several routes for the synthesis of $m$-terphenyl thio-, seleno-, and telluroethers were investigated. $m$-Terphenyl iodides react with diphenyl diselenides or ditellurides $\left(\mathrm{CsOH} \cdot \mathrm{H}_{2} \mathrm{O}, \mathrm{DMSO}, 110^{\circ} \mathrm{C}\right)$ to give the desired compounds in $19-84 \%$ yield which significantly extends the previously reported such reactions because $o$-benzyne cannot be an intermediate as previously suggested. However, the most general synthetic route was that involving reaction of 2,6-diaryl Grignard reagents with sulfur, selenium, or tellurium electrophiles. The $m$-terphenyl thio-, seleno-, and telluroethers were characterized spectroscopically and, in one case, by single-crystal X-ray analysis. Certain of these compounds showed atropisomerism and barriers for interconversion of isomers were determined by variable-temperature NMR spectroscopy. The barriers for interconverting the syn and anti atropisomers increase on going from the analogous $\mathrm{S}$ to Se to Te compounds. Calculations on this isomerization revealed that the barriers are due to rotation about the aryl-aryl bond and that the barriers for rotation about the aryl-chalcogen bond are much lower.

\section{Introduction}

Little is known about the chemical consequences of through-space interaction of chalcogenoethers and aromatic $\pi$-systems, in particular, whether chalcogen lone pairaromatic $\pi$-interactions would result in lowered oxidation potentials. To investigate this issue, $m$-terphenyl chalcogenoethers 1-3 were synthesized and characterized. Only two phenyl-chalcogenoethers with two flanking $o$-aryl groups have been previously reported: $2,4,6-\mathrm{Ph}_{3} \mathrm{C}_{6} \mathrm{H}_{2} \mathrm{SMe}, \mathbf{1 i},{ }^{1}$ and 2,6 (o-MeO- $p$ - $\left.t-\mathrm{BuC}_{6} \mathrm{H}_{3}\right)-4-\mathrm{Me}-\mathrm{C}_{6} \mathrm{H}_{2} \mathrm{SMe}, \mathbf{1 j}$ (Table 1). ${ }^{2}$ However, analogous thiols, selenols, and metal complexes ${ }^{3}$ as well as a ditelluride have been made. $m$-Terphenylthiol $\mathbf{1 k}$

(1) Suzuki, Y.; Toda, T.; Mukai, T. Heterocycles 1976, 4, 739-742.

(2) Bryant, J. A.; Helgeson, R. C.; Knobler, C. B.; de Grandpre, M. P.; Cram, D. J. J. Org. Chem. 1990, 55, 4622-4634.

(3) (a) Twamley, B.; Haubrich, S. T.; Power, P. P. Adv. Organomet. Chem. 1999, 44, 1-65. (b) Clyburne, J.; McMullen, A. C. Coord. Chem. Rev. 2000, 210, 73-99. is well-known. It has been synthesized ${ }^{4}$ via a NewmanKwart rearrangement starting from 2,6-diphenylphenol. The preparation of $2,4,6-\mathrm{Ph}_{3} \mathrm{C}_{6} \mathrm{H}_{2} \mathrm{SH}, \mathbf{1 1},{ }^{5}$ involves treatment of 2,4,6- $\mathrm{Ph}_{3} \mathrm{C}_{6} \mathrm{H}_{2} \mathrm{Li}\left(\mathrm{OEt}_{2}\right)_{2}$, obtained from 2,4,6$\mathrm{Ph}_{3} \mathrm{C}_{6} \mathrm{H}_{2} \mathrm{Br}$ in turn made by bromination of $2,4,6-\mathrm{Ph}_{3} \mathrm{C}_{6} \mathrm{H}_{3}$, with elemental sulfur. Similarly reaction of 2,6-di(p-tolyl)phenyl magnesium bromide with elemental sulfur provided thiophenol 1m. ${ }^{6}$ However, it should be noted that the Grignard reagent was obtained by sequential treatment of 1,3-dichlorobenzene with $n$-BuLi followed by $p$-tolyl-magnesium bromide, which is an advantageous method reported by Saednya and Hart. ${ }^{7}$

(4) (a) Bishop, P. T.; Dilworth, J. R.; Zubieta, J. A. Chem. Commun. 1985, 257-259. (b) Bishop, P. T.; Dilworth, J. R.; Nicholson, T.; Zubieta, J. Dalton Trans. 1991, 385-392. (c) Lawson Daku, L. M.; Pécaut, J.; LenormandFoucaut, A.; Vieux-Melchior, B.; Iveson, P.; Jordanov, J. Inorg. Chem. 2003 42, 6824-6850. (d) Moseley, J. D.; Lenden, P. Tetrahedron 2007, 63, 41204125 . 598.
(5) Ruhlandt-Senge, K.; Power, P. P. Bull. Soc. Chim. Fr. 1992, 129, 594 
TABLE 1. Compounds Synthesized in this Study and Reported in the Literature $^{a}$
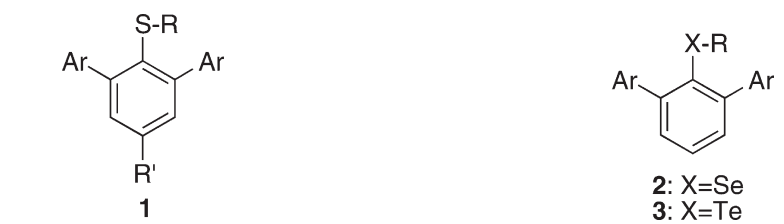

\begin{tabular}{lllllll}
\hline & $\mathrm{R}$ & $\mathrm{R}^{\prime}$ & \multicolumn{1}{c}{$\mathrm{Ar}$} & & $\mathrm{R}$ & \multicolumn{1}{c}{$\mathrm{Ar}$} \\
\hline $\mathbf{1 a}$ & $\mathrm{Me}$ & $\mathrm{H}$ & $o-\mathrm{MeOC}_{6} \mathrm{H}_{4}$ & $\mathbf{2 a}$ & $\mathrm{Me}$ & $o-\mathrm{MeOC}_{6} \mathrm{H}_{4}$ \\
$\mathbf{1 b}$ & $\mathrm{Me}$ & $\mathrm{H}$ & $m-\mathrm{MeOC}_{6} \mathrm{H}_{4}$ & $\mathbf{2 b}$ & $\mathrm{Me}$ & $p-\mathrm{MeOC}_{6} \mathrm{H}_{4}$ \\
$\mathbf{1 c}$ & $\mathrm{Me}$ & $\mathrm{H}$ & $p-\mathrm{MeOC}{ }_{6} \mathrm{H}_{4}$ & $\mathbf{2 c}$ & $\mathrm{Me}$ & $2,5-(\mathrm{MeO})_{2} \mathrm{C}_{6} \mathrm{H}_{3}$ \\
$\mathbf{1 d}$ & $\mathrm{Me}$ & $\mathrm{H}$ & $\mathrm{Ph}$ & $\mathbf{2 d}$ & $\mathrm{Ph}$ & $\mathrm{Ph}$ \\
$\mathbf{1 e}$ & $\mathrm{Me}$ & $\mathrm{Me}$ & $\mathrm{Ph}$ & $\mathbf{2 e}$ & $\mathrm{Ph}$ & $o-\mathrm{MeOC}_{6} \mathrm{H}_{4}$ \\
$\mathbf{1 f}$ & $\mathrm{Me}$ & $\mathrm{H}$ & $2,5-(\mathrm{MeO})_{2} \mathrm{C}_{6} \mathrm{H}_{3}$ & $\mathbf{2 f}$ & $\mathrm{Ph}$ & $p-\mathrm{MeOC}_{6} \mathrm{H}_{4}$ \\
$\mathbf{1 g}$ & $\mathrm{Me}$ & $\mathrm{H}$ & $2-\mathrm{naphthyl}$ & $\mathbf{2 g}$ & $\mathrm{Ph}$ & $2,5-\left(\mathrm{MeO}_{2} \mathrm{C}_{6} \mathrm{H}_{3}\right.$ \\
$\mathbf{1 h}$ & $\mathrm{Ph}$ & $\mathrm{H}$ & $o-\mathrm{MeOC}{ }_{6} \mathrm{H}_{4}$ & $\mathbf{2 h}$ & $\mathrm{H}$ & $2,4,6-\mathrm{Ph}_{3} \mathrm{C}_{6} \mathrm{H}_{2}$ \\
$\mathbf{1 i}^{1}$ & $\mathrm{Me}$ & $\mathrm{Ph}$ & $\mathrm{Ph}$ & $\mathbf{2 i}$ & $\mathrm{H}$ & $2,4,6-\mathrm{Me}_{3} \mathrm{C}_{6} \mathrm{H}_{2}$ \\
$\mathbf{1 j}^{2}$ & $\mathrm{Me}$ & $\mathrm{Me}$ & $o-\mathrm{MeO}-p-t-\mathrm{BuC}_{6} \mathrm{H}_{3}$ & $\mathbf{2 j} \mathbf{j}^{13}$ & $\mathrm{H}$ & $2,6-\left(i-\mathrm{Pr}_{2} \mathrm{C}_{6} \mathrm{H}_{3}\right.$ \\
$\mathbf{1 k}^{4}$ & $\mathrm{H}$ & $\mathrm{H}$ & $\mathrm{Ph}$ & $\mathbf{3 a}$ & $\mathrm{Me}$ & $o-\mathrm{MeOC}{ }_{6} \mathrm{H}_{4}$ \\
$\mathbf{1 l}^{5}$ & $\mathrm{H}$ & $\mathrm{Ph}$ & $\mathrm{Ph}$ & $\mathbf{3 b}$ & $\mathrm{Me}$ & $2,5-\left(\mathrm{MeO}_{2} \mathrm{C}_{6} \mathrm{H}_{3}\right.$ \\
$\mathbf{1 m}^{6}$ & $\mathrm{H}$ & $\mathrm{H}$ & $p-\mathrm{MeC} \mathrm{H}_{4}$ & $\mathbf{3 c}$ & $\mathrm{Ph}$ & $\mathrm{Ph}$ \\
$\mathbf{1 n}^{8}$ & $\mathrm{H}$ & $\mathrm{H}$ & $2,4,6-\mathrm{Me} \mathrm{C}_{6} \mathrm{H}_{2}$ & $\mathbf{3 d}$ & $\mathrm{Ph}$ & $o-\mathrm{MeOC} \mathrm{H}_{4}$ \\
$\mathbf{1 0}^{9}$ & $\mathrm{H}$ & $\mathrm{H}$ & $2,4,6-(i-\mathrm{Pr})_{3} \mathrm{C}_{6} \mathrm{H}_{2}$ & $\mathbf{3 e}$ & $\mathrm{Ph}$ & $1-n a p h t h y l$ \\
& & & & $\mathbf{3 f}$ & $\mathrm{Ph}$ & $p-\mathrm{MeC}_{6} \mathrm{H}_{4}$
\end{tabular}

${ }^{a}$ For the known compounds the literature reference is given as a superscript.

Similarly, 2,6- $\left(2^{\prime}, 4^{\prime}, 6^{\prime}-\mathrm{Me}_{3} \mathrm{C}_{6} \mathrm{H}_{2}\right)_{2} \mathrm{C}_{6} \mathrm{H}_{3} \mathrm{SH}, \mathbf{1 n},{ }^{8}$ and 2,6$\left(2^{\prime}, 4^{\prime}, 6^{\prime}-i-\mathrm{Pr}_{3} \mathrm{C}_{6} \mathrm{H}_{2}\right){ }_{3} \mathrm{C}_{6} \mathrm{H}_{3} \mathrm{SH}, 10,{ }^{9}$ were obtained by reaction of the corresponding aryl lithium with elemental sulfur. Synthesis of 2,4,6- $\mathrm{Ph}_{3} \mathrm{C}_{6} \mathrm{H}_{2} \mathrm{SeH}, \mathbf{2 h}$, was achieved by sequential bromination, lithiation with $n$-BuLi, and reaction with elemental selenium of $1,3,5-\mathrm{Ph}_{3} \mathrm{C}_{6} \mathrm{H}_{3} \cdot{ }^{10}$ The corresponding diselenide was also reported by the reaction of $2,4,6-\mathrm{Ph}_{3}$ $\mathrm{C}_{6} \mathrm{H}_{2} \mathrm{MgBr}$ with elemental selenium. ${ }^{11}$ The preparation of 2,6- $\left(2^{\prime}, 4^{\prime}, 6^{\prime}-\mathrm{Me}_{3} \mathrm{C}_{6} \mathrm{H}_{2}\right) \mathrm{C}_{6} \mathrm{H}_{3} \mathrm{SeH},{ }^{12} \mathbf{2 i}$, and 2,6- $\left(2^{\prime}, 6^{\prime}-i-\mathrm{Pr}_{2} \mathrm{C}_{6^{-}}\right.$ $\left.\mathrm{H}_{3}\right) \mathrm{C}_{6} \mathrm{H}_{3} \mathrm{SeH}, 2 \mathbf{j}$, ${ }^{13}$ paralleled that of their sulfur analogues thiophenols $1 \mathrm{n}$ and 1o, respectively, except that selenium was used instead of sulfur. Finally, $\left[2,4,6-\mathrm{Ph}_{3} \mathrm{C}_{6} \mathrm{H}_{2} \mathrm{Te}\right]_{2}$ was made by reaction of the corresponding Grignard reagent with elemental tellurium. ${ }^{14}$

It is anticipated that the two flanking phenyl groups in the $m$-terphenyl chalcogenoethers will adopt a perpendicular conformation such as in structure $\mathbf{A}$ below, which allows for chalcogen lone pair-arene $\pi$ through-space interaction in the radical cations. This paper reports the synthesis and structural characterization of $m$-terphenylthioethers $\mathbf{1 a}-\mathbf{i}$, as well as the related seleno- and telluroethers $\mathbf{2 a}-\mathbf{g}$ and

(6) Ohta, S.; Ohki, Y.; Ikagawa, Y.; Suizu, R.; Tatsumi, K. J. Organomet. Chem. 2007, 692, 4792-4799.

(7) Saednya, A.; Hart, H. Synthesis 1996, 1455-1458.

(8) Ellison, J. J.; Ruhlandt-Senge, K.; Power, P. P. Angew. Chem., Int. Ed. 1994, 33, 1178-1180.

(9) Niemeyer, M.; Power, P. P. Inorg. Chem. 1996, 35, 7264-7272.

(10) Hauptmann, R.; Kliss, R.; Schneider, J.; Henkel, G. Z. Anorg. Allg. Chem. 1998, 624, 1927-1936.

(11) Kataeva, L. M.; Kataev, E. G. Zh. Obshch. Khim. 1962, 32, 2710 2713

(12) Ellison, J. J.; Ruhlandt-Senge, K.; Hope, H. H.; Power, P. P. Inorg. Chem. 1995, 34, 49-54.

(13) Niemeyer, M.; Power, P. P. Inorg. Chim. Acta 1997, 263, 201-207.

(14) Schulz Lang, E.; Maichle-Mössmer, C.; Strähle, J. Z. Anorg. Allg. Chem. 1994, 620, 1678-1685.

(15) Ammam, M.; Zakai, U. I.; Wilson, G. S.; Glass, R. S. Pure Appl. Chem. 2010, 82, 555-563.
SCHEME 1. Synthesis of $m$-Terphenyl- and Substituted m-Terphenylchalcogenoethers

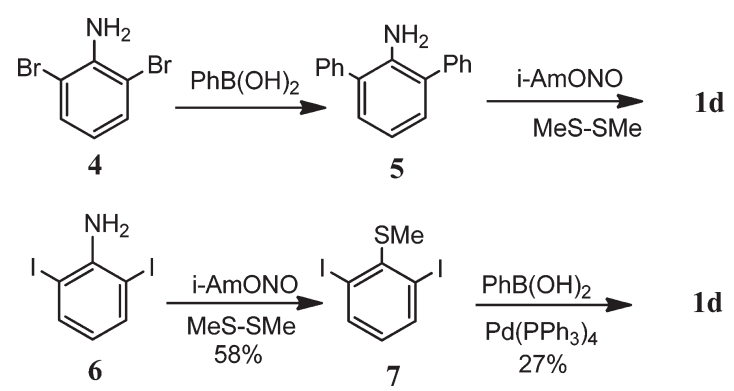

$\mathbf{3 a}-\mathbf{f}$, respectively. In another paper ${ }^{15}$ cyclic voltammetric studies reveal that the irreversible oxidation potentials for thioethers $\mathbf{1} \mathbf{a}, \mathbf{c}, \mathbf{d}, \mathbf{f}$, and $\mathbf{g}$ and selenoethers $\mathbf{2} \mathbf{a}$ and $\mathbf{2} \mathbf{b}$ but not telluroethers $\mathbf{3 d}$ and $\mathbf{3 e}$ are less positive than expected on the basis of models. This suggests possible through-space $\mathrm{S}$ and $\mathrm{Se} \cdot \cdots \pi$ interaction. In addition, analysis of the photoelectron spectrum of $\mathbf{1 d}$ shows that its HOMO is a combination of sulfur lone pair and $\pi$-MO.

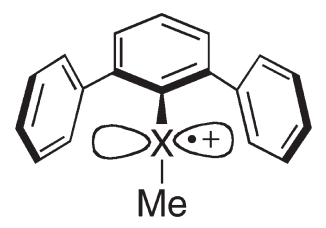

A

\section{Results and Discussion}

Syntheses. $m$-Terphenylmethylthioether 1d was synthesized as shown in eq 1 of Scheme 1 in $42 \%$ yield after purification. The alternative sequence, that is, introduction of the thioether moiety followed by Suzuki coupling, as shown in eq 2, produced thioether 1e. Although these routes provided the best syntheses of thioethers $\mathbf{1 d}$ and $\mathbf{1 e}$, an alternative method based on the $m$-terphenyl synthesis reported by Saednya and $\mathrm{Hart}^{7}$ proved to be the most generally useful for our purposes. Reaction of 1,3-dichlorobenzene $\mathbf{8}$ with $n$-butyllithium followed by an aryl Grignard reagent affords $m$-terphenyl and substituted $m$-terphenyl Grignard reagents 9 as shown in Table 2. The mechanism suggested ${ }^{7}$ for formation of Grignard 9 from 1,3-dichlorobenzene $\mathbf{8}$ is shown in Scheme 2. This intermediate was shown to react with $\mathrm{H}^{+}$ or $\mathrm{I}_{2}$ to give the corresponding $m$-terphenyl or substituted $m$-terphenyl or substituted $m$-terphenyliodide, respectively. Reaction of Grignard 9 with $\mathrm{MeSSO}_{2} \mathrm{Me}, \mathrm{PhSSPh}, \mathrm{MeSe}-$ $\mathrm{SeMe}, \mathrm{PhSeSePh}, \mathrm{MeTeTeMe}$, or PhTeTePh afforded the corresponding chalcogenoether in the yield listed in Table 2.

Since it had been reported ${ }^{16}$ that reaction of bromo- or iodobenzene with diphenyl diselenide or diphenyl disulfide with $\mathrm{CsOH} \cdot \mathrm{H}_{2} \mathrm{O}$ in DMSO afforded diphenyl selenide or diphenyl sulfide, respectively, in $64-70 \%$ yield, the reaction of substituted $m$-terphenyl iodides with diphenyl dichalcogenides was studied. Remarkably, $m$-terphenyl and substituted $m$-terphenylchalcogenides were formed in $19-84 \%$

(16) Varala, R.; Ramu, E.; Adapa, S. R. Bull. Chem. Soc. Jpn. 2006, 79, $140-141$. 
TABLE 2. Synthesis of Compounds $1-3$ by Reaction of Grignard Reagent 9 with $\mathrm{MeSSO}_{2} \mathrm{Me}$ or $\mathrm{RXXR}(\mathrm{R}=\mathrm{Me}, \mathrm{Ph} ; \mathrm{X}=\mathrm{S}$, Se, Te $)$

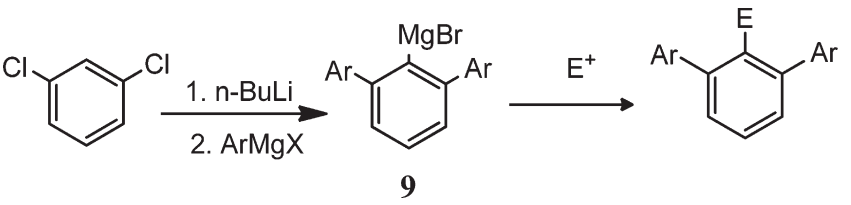

\begin{tabular}{|c|c|c|c|}
\hline $\mathrm{Ar}$ & electrophile & product & yield $(\%)$ \\
\hline$o-\mathrm{MeOC}_{6} \mathrm{H}_{4}$ & $\mathrm{MeSSO}_{2} \mathrm{Me}$ & 1a & 67 \\
\hline$m-\mathrm{MeOC}_{6} \mathrm{H}_{4}$ & $\mathrm{MeSSO}_{2} \mathrm{Me}$ & 1b & 74 \\
\hline$p-\mathrm{MeOC}_{6} \mathrm{H}_{4}$ & $\mathrm{MeSSO}_{2} \mathrm{Me}$ & 1c & 16 \\
\hline $2,5-(\mathrm{MeO})_{2} \mathrm{C}_{6} \mathrm{H}_{3}$ & $\mathrm{MeSSO}_{2} \mathrm{Me}$ & 1f & 26 \\
\hline 2-naphthyl & $\mathrm{MeSSO}_{2} \mathrm{Me}$ & $1 g$ & 59 \\
\hline$o-\mathrm{MeOC}_{6} \mathrm{H}_{4}$ & $\mathrm{PhSSPh}$ & $1 \mathrm{~h}$ & 54 \\
\hline$o-\mathrm{MeOC}_{6} \mathrm{H}_{4}$ & MeSeSeMe & $2 \mathbf{a}$ & 30 \\
\hline$p-\mathrm{MeOC}_{6} \mathrm{H}_{4}$ & MeSeSeMe & $2 \mathrm{~b}$ & 34 \\
\hline $2,5-(\mathrm{MeO})_{2} \mathrm{C}_{6} \mathrm{H}_{3}$ & MeSeSeMe & $2 c$ & 64 \\
\hline $\mathrm{C}_{6} \mathrm{H}_{5}$ & $\mathrm{PhSeSePh}$ & 2d & 46 \\
\hline$o-\mathrm{MeOC}_{6} \mathrm{H}_{4}$ & $\mathrm{PhSeSePh}$ & $2 e$ & 62 \\
\hline$p-\mathrm{MeOC}_{6} \mathrm{H}_{4}$ & $\mathrm{PhSeSePh}$ & $2 f$ & 45 \\
\hline $2,5-(\mathrm{MeO})_{2} \mathrm{C}_{6} \mathrm{H}_{3}$ & $\mathrm{PhSeSePh}$ & $2 \mathrm{~g}$ & 29 \\
\hline$o-\mathrm{MeOC}_{6} \mathrm{H}_{4}$ & MeTeTeMe & 3a & 69 \\
\hline $3,5-(\mathrm{MeO})_{2} \mathrm{C}_{6} \mathrm{H}_{3}$ & MeTeTeMe & $3 b$ & 37 \\
\hline $\mathrm{C}_{6} \mathrm{H}_{5}$ & $\mathrm{PhTeTePh}$ & $3 c$ & 67 \\
\hline$o-\mathrm{MeOC}_{6} \mathrm{H}_{4}$ & $\mathrm{PhTeTePh}$ & 3d & 21 \\
\hline 1-naphthyl & PhTeTePh & $3 e$ & 24 \\
\hline$p-\mathrm{MeC}_{6} \mathrm{H}_{4}$ & PhTeTePh & $3 f$ & 41 \\
\hline
\end{tabular}

SCHEME 2. Mechanism for Formation of Grignard 9 from 1,3Dichlorobenzene 8

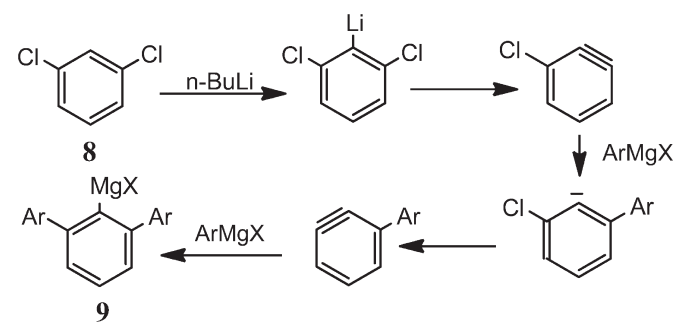

yield as seen in Table 3. The reaction was unsuccessful with diphenyl disulfide, di(4-aminophenyl) disulfide, and di(4-nitrophenyl) disulfide with any of the substituted $m$-terphenyl iodides listed in Table 3. However, in our hands, in another process that had literature precedents with simpler aryl halides, ${ }^{17} 4$-methylthiophenol reacted with $m$-terphenyl iodide to give the corresponding sulfide in $33 \%$ yield. This reaction was unsuccessful or gave trace amounts of the desired products with the other substituted $m$-terphenyl iodides listed in Table 3, as well as with other thiols (4-amino-, 4-methoxy-, and 4-nitrophenylthiol, 1-butanethiol, and 2-mercaptoethanol). Since it had been suggested ${ }^{18}$ that this reaction occurs via a benzyne intermediate, our results show that another mechanism must be operative with substituted $m$-terphenyl iodides, which cannot eliminate to form $o$-benzyne. Since a frequently encountered product in our reactions is the substituted $m$-terphenyl in which iodine is replaced by hydrogen, a free radical mechanism via the sub-

(17) Varala, R.; Ramu, E.; Alam, M. M.; Adapa, S. R. Chem. Lett. 2004, $33,1614-1615$.

(18) Varala, R.; Ramu, E.; Alam, M. M.; Adapa, S. R. Synlett 2004 $1747-1750$.
TABLE 3. Reaction of $\boldsymbol{m}$-Terphenyl Iodide and Substituted $\boldsymbol{m}$-Terphenyl Iodides, 2,6- $\mathrm{Ar}_{2} \mathrm{C}_{6} \mathrm{H}_{3} \mathrm{I}$, with Diphenyldichalcogenides, $\mathrm{PhXXPh}$, and $\mathrm{CsOH} \cdot \mathrm{H}_{2} \mathrm{O}$ in DMSO $\left(110^{\circ}, 24-27 \mathrm{~h}\right)$

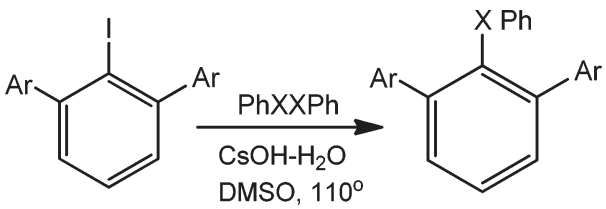

\begin{tabular}{llcc}
\hline $\mathrm{Ar}$ & $\mathrm{X}$ & product & yield (\%) \\
\hline $\mathrm{Ph}$ & $\mathrm{Se}$ & $\mathbf{2 d}$ & 58 \\
$4-\mathrm{MeO}$ & $\mathrm{Te}$ & $\mathbf{3 c}$ & 84 \\
$2-\mathrm{MeO}$ & $\mathrm{Se}$ & $\mathbf{2 f}$ & 19 \\
& $\mathrm{Se}$ & $\mathbf{2 e}$ & \\
& $\mathrm{Te}$ & $\mathbf{3 d}$ & 25 \\
\hline
\end{tabular}

stituted $m$-terphenyl radical appears feasible; although a nucleophilic addition-elimination pathway is also possible, especially in view of the successful reaction with 4-methylthiophenol.

To explore the generality of this reaction, reaction of the substituted $m$-terphenyl iodides listed in Table 3 with a variety of secondary amines (aniline, indoline, indole, carbazole, morpholine, piperidine, and $N$-phenylpiperazine) and $\mathrm{CsOH} \cdot \mathrm{H}_{2} \mathrm{O}$ in DMSO was monitored by GC-MS. Little or no desired product was obtained. Similarly, reaction of 2,6-dimethylphenyliodide, -bromide, or -chloride with $\mathrm{Ph}_{2} \mathrm{X}_{2}(\mathrm{X}=\mathrm{S}, \mathrm{Se}, \mathrm{Te})$ or $4-\mathrm{XC}_{6} \mathrm{H}_{4} \mathrm{SH}\left(\mathrm{X}=\mathrm{H}, \mathrm{Me}, \mathrm{NH}_{2}\right.$, $\mathrm{OMe}, \mathrm{NO}_{2}$ ) or 1-butanethiol or 2-mercaptoethanol or secondary amines and $\mathrm{CsOH} \cdot \mathrm{H}_{2} \mathrm{O}$ in DMSO gave little or no desired product with one exception: reaction of 2,6-dimethylphenyliodide, $\mathrm{PhTeTePh}$, and $\mathrm{CsOH} \cdot \mathrm{H}_{2} \mathrm{O}$ in DMSO produced phenyl-2,6-dimethylphenyltelluride in $41 \%$ yield. Similarly, reactions of 2,6-dimethoxyphenyliodide, iodophenyl-2,4,6-tricarboxylic acid, or bromo or chloro phenyl2,6-dicarboxylic acid with $\mathrm{Ph}_{2} \mathrm{X}_{2}(\mathrm{X}=\mathrm{S}, \mathrm{Se}, \mathrm{Te})$ or $4-\mathrm{XC}_{6} \mathrm{H}_{4} \mathrm{SH}$ $\left(\mathrm{X}=\mathrm{H}, \mathrm{Me}, \mathrm{NH}_{2}, \mathrm{OMe}, \mathrm{NO}_{2}\right.$ ) or 1-butanethiol or 2-mercaptoethanol or secondary amines and $\mathrm{CsOH} \cdot \mathrm{H}_{2} \mathrm{O}$ in DMSO were unsuccessful.

NMR Spectroscopy. The structures of the substituted $m$-terphenyl methyl and phenylchalcogenides synthesized were determined by spectroscopic analysis (IR, ${ }^{1} \mathrm{H}$ and ${ }^{13} \mathrm{C}$ NMR), mass spectrometry including high resolution MS, and in one case, by single crystal X-ray diffraction analysis. An interesting feature of the ${ }^{1} \mathrm{H}$ NMR spectrum of thioether 1a in $\mathrm{CD}_{2} \mathrm{Cl}_{2}$ is that there are two methoxy peaks at room temperature as seen in Figure 1.

This is expected if the flanking phenyl rings are orthogonal to the central one (such as in geometry A), owing to atropisomerism. In this situation, there are syn and anti isomers, as illustrated in Figure 2. Indeed one of these conformations is adopted in the solid state, as seen in the single crystal X-ray crystal structure analysis of thioether 1a shown in Figure 3, in which the anti isomer is evident. The angles between the central benzene ring and the mean planes through the $o$-methoxyphenyl rings are $75.49(4)^{\circ}$ and $80.41(5)^{\circ}$. The angle between the central benzene ring and the plane of the methyl $\mathrm{C}, \mathrm{S}$, and aromatic carbon to which the sulfur is bonded is $69.37(9)^{\circ}$.

Variable-temperature ${ }^{1} \mathrm{H}$ NMR spectroscopic studies provide more insight into this atropisomerism. The low boiling point of $\mathrm{CD}_{2} \mathrm{Cl}_{2}$ limits high-temperature NMR studies for thioether 1a, but in DMSO- $d_{6}$ the OMe signals coalesce near 


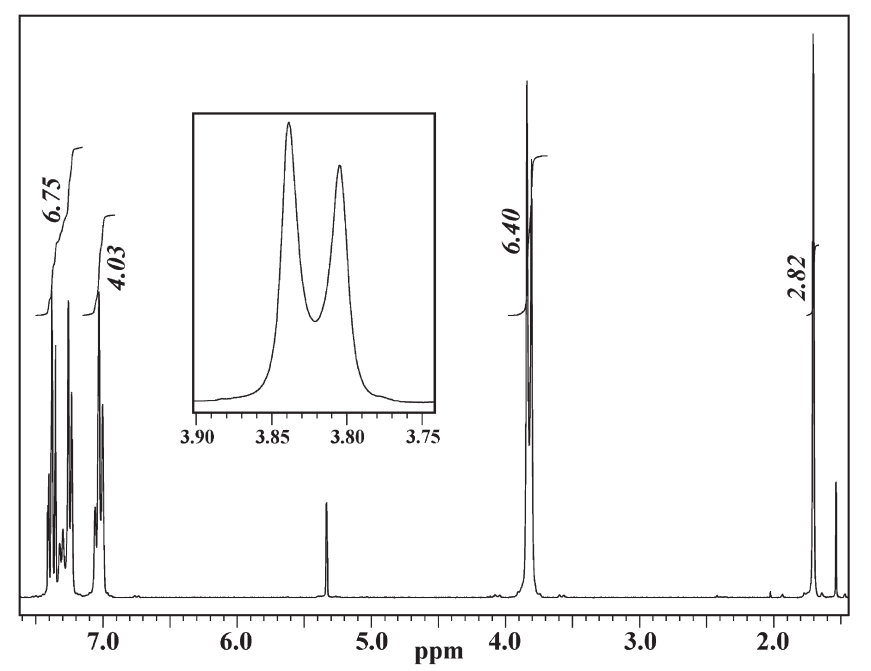

FIGURE 1. $300 \mathrm{MHz}{ }^{1} \mathrm{H}$ NMR spectrum of $\mathbf{1 a}$ in $\mathrm{CD}_{2} \mathrm{Cl}_{2}$ at ambient temperature (inset showing expanded $\mathrm{OMe}$ region).

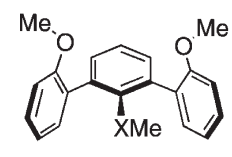

syn

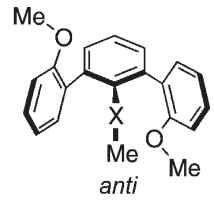

FIGURE 2. Syn and anti atropisomers of methoxy-substituted $m$-terphenylchalcogenoethers.

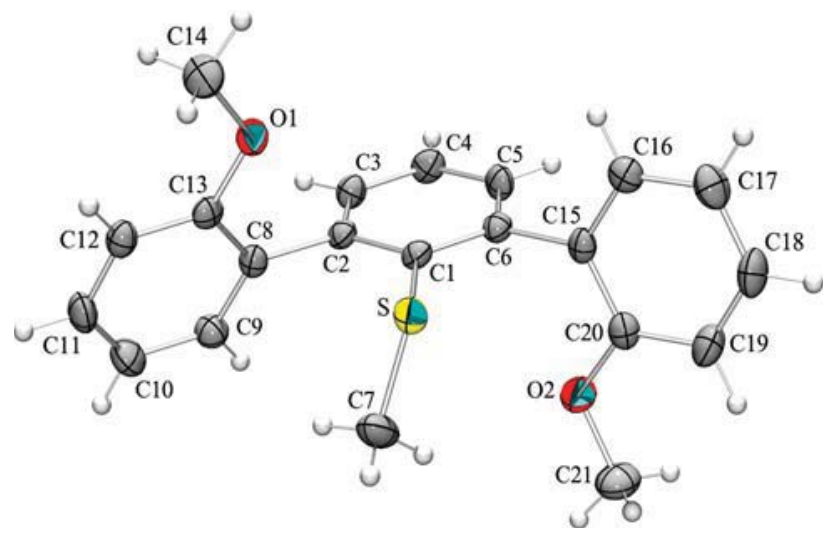

FIGURE 3. Molecular structure of thioether 1a from X-ray crystallographic structure analysis.

$30^{\circ}$ (as seen in the stacked plot in the Supporting Information). On cooling a solution of thioether 1a in $\mathrm{CD}_{2} \mathrm{Cl}_{2}$, the $\mathrm{SMe}$ signal split into two signals as shown in Figure 4. The barrier for interconversion of the $m$-methoxy analogue thioether $\mathbf{1 b}$ is much lower than that for thioether 1a. Consequently, there is one peak for the methoxy groups at ambient temperature, which broadens and separates into two peaks at low temperature in $\mathrm{CD}_{2} \mathrm{Cl}_{2}$ (see Supporting Information). The $p$-methoxy analogue is incapable of atropisomerism and shows one peak for the methoxy groups at all temperatures.

The selenium and tellurium analogues with $o$-methoxy groups, $\mathbf{2} \mathbf{a}$ and $\mathbf{3 a}$, respectively, show even higher coalescence temperatures in DMSO- $d_{6}$ than for thioether 1a, and stacked plots for these compounds are shown in Figures 5 and 6 , respectively, illustrating their collapse to a single peak

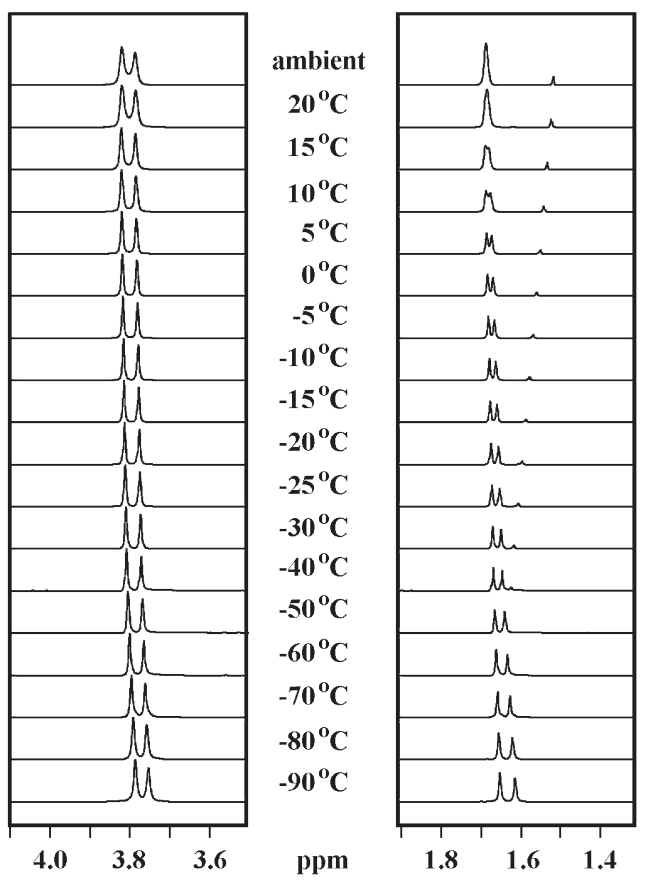

FIGURE 4. Variable-temperature $300 \mathrm{MHz}{ }^{1} \mathrm{H}$ NMR spectroscopic study of thioether $1 \mathrm{a}$ in $\mathrm{CD}_{2} \mathrm{Cl}_{2}(\mathrm{OMe}$ region on left, $\mathrm{SMe}$ region on right).

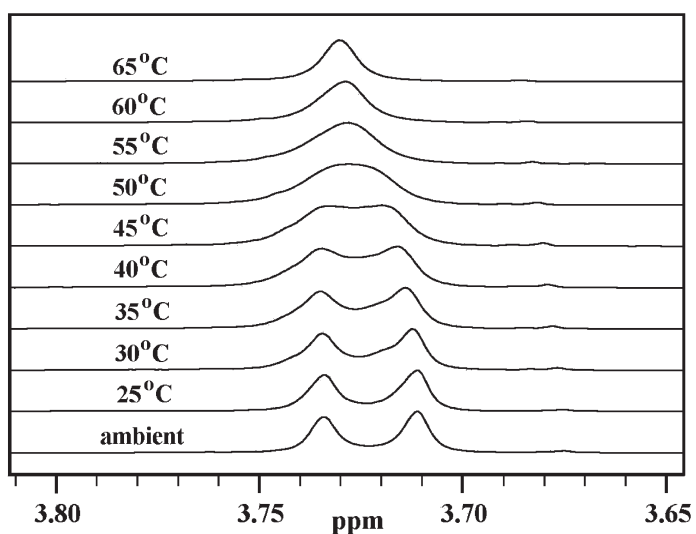

FIGURE 5. Variable-temperature $300 \mathrm{MHz}{ }^{1} \mathrm{H}$ NMR spectroscopic study of selenoether 2a in DMSO- $d_{6}$ (OMe region).

on increasing the temperature. ${ }^{19}$ Similarly the ${ }^{1} \mathrm{H}$ NMR signal for the -SMe moiety in thioether 1a is a broad singlet at ambient temperature, but the $\mathrm{SeMe}$ (2a) and TeMe (3a) signals at ambient temperature are two peaks that coalesce on warming (see Figures 7 and 8, respectively).

The $o$-methoxy Ph-chalcogen compounds $\mathbf{1 h}, \mathbf{2 e}$, and $\mathbf{3 d}$ also show two methoxy peaks that collapse into one on warming (see Supporting Information for stacked plots). The ${ }^{13} \mathrm{C}$ NMR spectra for all of the $o$-methoxy compounds $\mathbf{1 a}, \mathbf{1 h}$, 2a, 2e, 3a, and 3d show two peaks for the $\mathrm{MeO}$ carbons at ambient temperature. In addition, the ${ }^{77} \mathrm{Se}$ NMR spectra of selenoethers $\mathbf{2 a}$ and $\mathbf{2 e}$ show two Se signals at room temperature at $\delta 374.7$ and 375.0 for $\mathbf{2 a}$ and 371.7 and 374.6 ppm for $\mathbf{2 e}$.

(19) Although the peak shapes observed for 1c and 3a can be fitted well using two atropisomers, those observed for $\mathbf{2 a}$ are not as well-fitted. A better fit is obtained using three atropisomers but the calculations outlined later in the paper do not support another conformer for $\mathbf{2 a}$. 


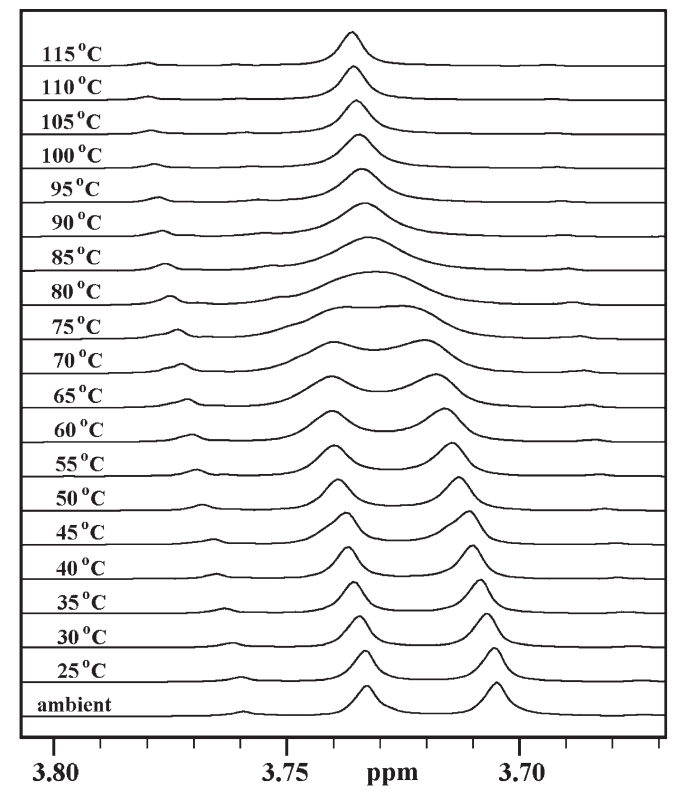

FIGURE 6. Variable-temperature $300 \mathrm{MHz}{ }^{1} \mathrm{H}$ NMR spectroscopic study of telluroether 3a in DMSO- $d_{6}$ (OMe region).

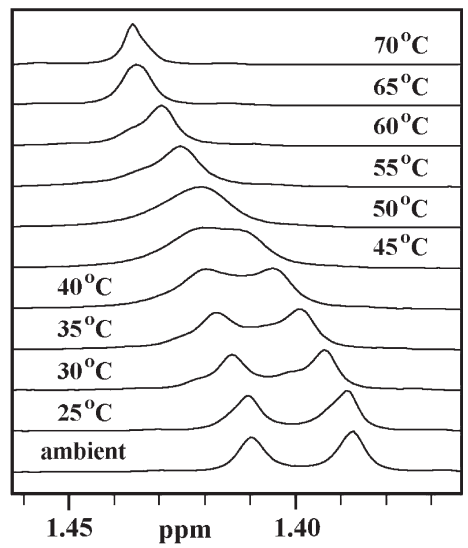

FIGURE 7. Variable-temperature $300 \mathrm{MHz}{ }^{1} \mathrm{H}$ NMR spectroscopic study of selenoether 2a in DMSO- $d_{6}$ (SeMe region).

Analysis of the coalescence data provided excellent fits of the observed spectra and calculated spectra. The fits around the critical coalescence temperatures for the OMe and SeMe signals for selenoether $\mathbf{2} \mathbf{a}$ and the OMe and TeMe signals for telluroether 3a are shown in Figure 9. The fitting parameters as well as the calculated barriers are listed in Table 4.

A detailed analysis of the barriers was required because the variable-temperature NMR spectra show that the chemical shifts vary significantly with temperature. This is dramatically illustrated for the Me-chalcogen signals in the spectra of selenoether $\mathbf{2} \mathbf{a}$ and telluroether $\mathbf{3 a}$ as seen in Figures 7 and 8 . The WinDNMR program (which predicts this variation) allowed fitting the parameters at each temperature and thus to determine the activation barriers for interconversions of the syn and anti atropisomers. Another important feature of these interconversions is that they are solvent-dependent, which is seen by comparing the ambient temperature spectra of thioether $1 \mathrm{a}$ in the OMe region in $\mathrm{CD}_{2} \mathrm{Cl}_{2}$ (Figure 1 insert) and DMSO- $d_{6}$ (see Figure 9). Thus the energy barriers

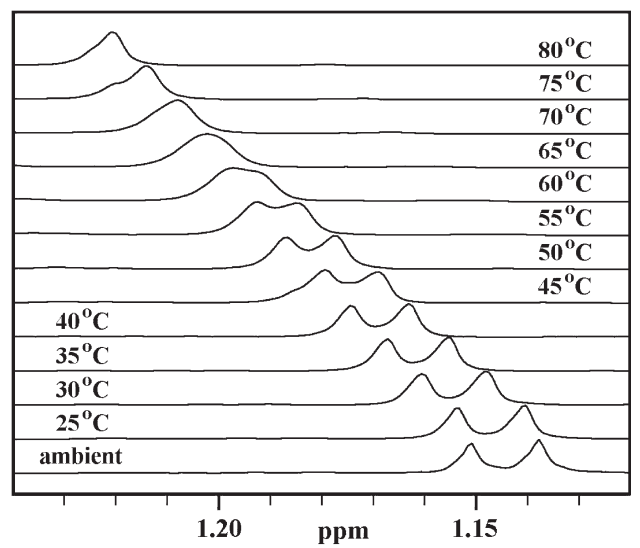

FIGURE 8. Variable-temperature $300 \mathrm{MHz}{ }^{1} \mathrm{H}$ NMR spectroscopic study of telluroether 3a in DMSO- $d_{6}$ (TeMe region).
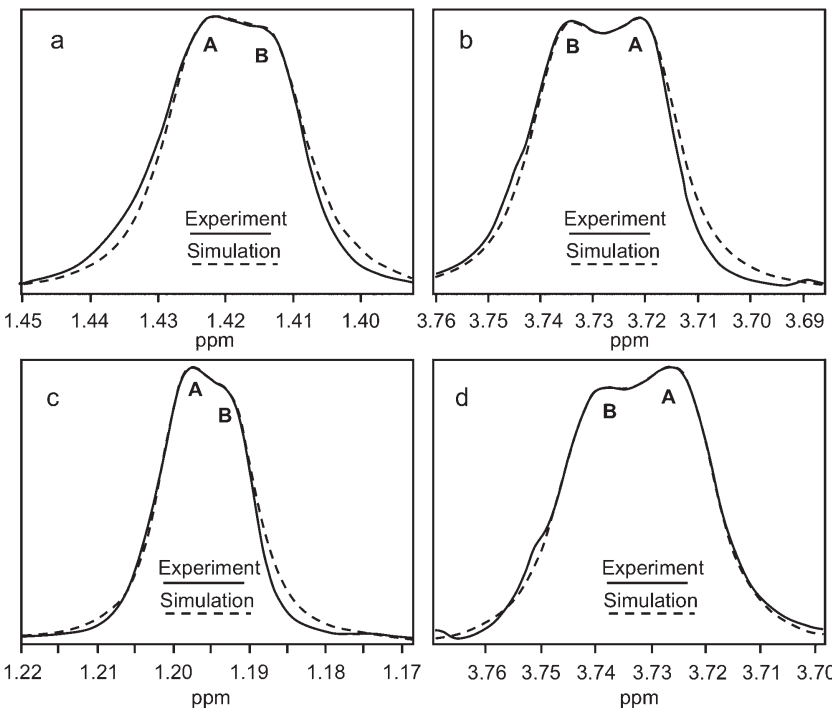

FIGURE 9. Experimental (solid lines) and simulated (broken lines) ${ }^{1} \mathrm{H}$ NMR peaks for selenoether $2 \mathrm{a}$ at $45 \mathrm{C}$ [(a) SeMe resonance, (b) the OMe resonance] and for telluroether $3 \mathbf{a}[$ [c) TeMe resonance at $60 \mathrm{C}$, (d) OMe resonance at $75 \mathrm{C}]$ in DMSO- $d_{6}$ near the coalescence temperatures (see Table 4 for parameters).

obtained for $\mathrm{MeO}$ coalescence for thioether 1a in DMSO$d_{6}$ cannot be directly compared with that for SMe coalescence in $\mathrm{CD}_{2} \mathrm{Cl}_{2}$.

It is interesting that the barriers for interconversion of the atropisomers increase on going from sulfur to selenium to tellurium. Thus, the increasing size of the chalcogen $(\mathrm{S}<$ $\mathrm{Se}<\mathrm{Te})^{20}$ and not the increasing aryl-chalcogen bond length $(\mathrm{S}-\mathrm{C}<\mathrm{Se}-\mathrm{C}<\mathrm{Te}-\mathrm{C})$, which would tend to reduce steric interaction, is key in determining the magnitude of this barrier. In addition, comparison of the variable-temperature ${ }^{1} \mathrm{H}$ NMR data for $\mathrm{Ph}$-chalcogen compounds $\mathbf{1 h}, \mathbf{2 e}$, and $\mathbf{3 d}$ (see Supporting Information) with that of the corresponding Me-chalcogen compounds (1a, 2a, and 3a, respectively) show comparable coalescence temperatures. Thus increasing the size of the substituent attached to the chalcogen $(\mathrm{Ph}>$ $\mathrm{Me})$ appears to have little or no effect. Perusal of Table 4 also

(20) The van der Waals radius for $\mathrm{S}, \mathrm{Se}$, and Te is 1.80, 1.90, and 2.06, respectively: Mantina, M.; Chamberlin, A. C.; Valero, R.; Cramer, C. J.; Truhlar, D. G. J. Phys. Chem. A 2009, 113, 5806-5812. 
TABLE 4. Fitting Parameters for Variable-Temperature ${ }^{1} \mathbf{H}$ NMR Spectra of Thioether 1a, Selenoether 2a, and Telluroether 3a near Coalescence

\begin{tabular}{|c|c|c|c|c|c|c|c|c|}
\hline compound & group & temp $\left({ }^{\circ} \mathrm{C}\right)$ & solvent & line width $(\mathrm{Hz})$ & $v_{\mathrm{A}}-v_{\mathrm{B}}(\mathrm{Hz})$ & $k_{\mathrm{AB}}+k_{\mathrm{BA}}\left(\mathrm{s}^{-1}\right)$ & $\% A$ & $\Delta G^{\ddagger}(\mathrm{A} \rightarrow \mathrm{B})(\mathrm{kJ} / \mathrm{mol})$ \\
\hline $1 \mathrm{a}$ & $\mathrm{SMe}$ & 15 & $\mathrm{CD}_{2} \mathrm{Cl}_{2}$ & 1.25 & 3.47 & 9.20 & 52.1 & 66.9 \\
\hline $2 a$ & $\mathrm{SeMe}$ & 45 & DMSO- $d_{6}$ & 2.00 & 5.01 & 16.8 & 51.1 & 72.5 \\
\hline $2 a$ & $\mathrm{OMe}$ & 45 & DMSO- $d_{6}$ & 2.00 & -6.68 & 20.3 & 50.3 & 71.9 \\
\hline $3 \mathbf{a}$ & $\mathrm{OMe}$ & 75 & DMSO- $d_{6}$ & 1.60 & -7.30 & 25.1 & 51.6 & 78.5 \\
\hline
\end{tabular}
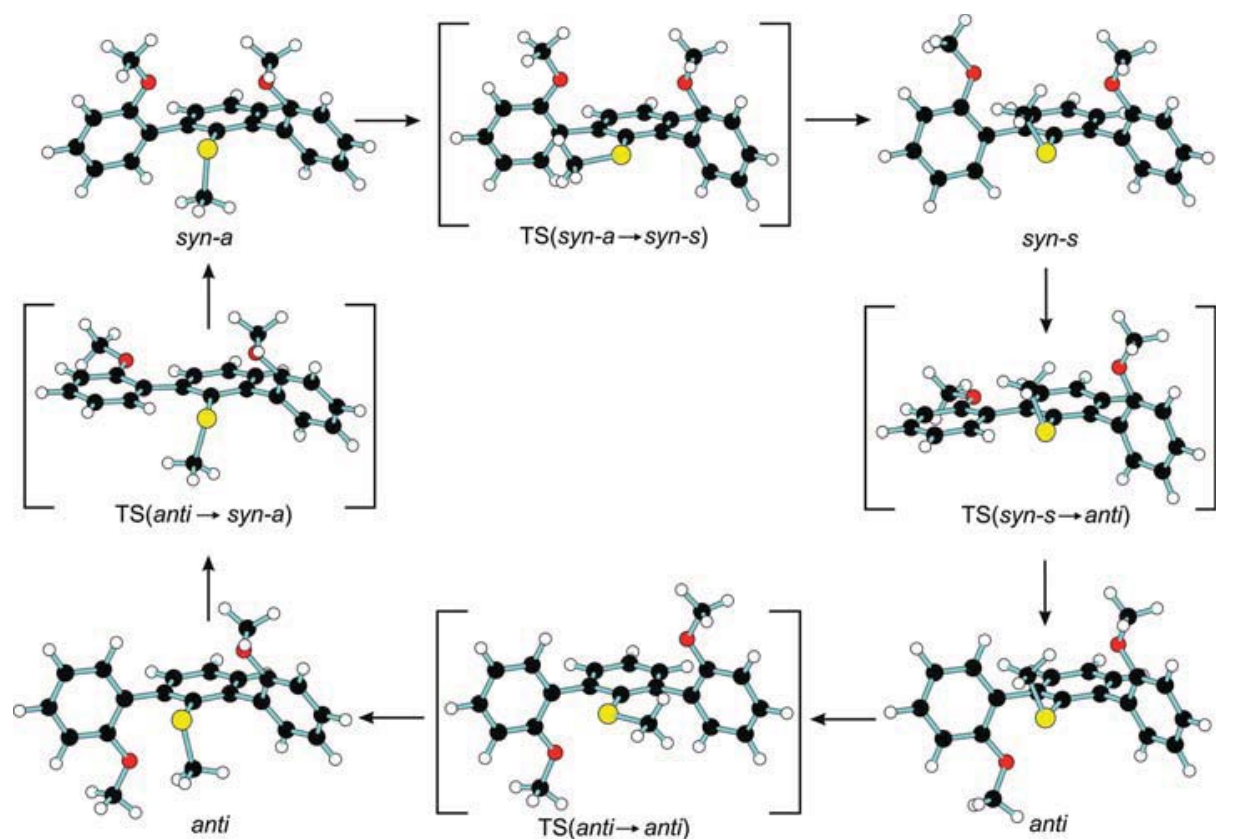

FIGURE 10. Interconversion of atropisomers of thioether 1a, selenoether 2a, and telluroether 3a (structures from B3LYP/6-31G* calculations for thioether 1a; note that the two anti structures are identical).

reveals that the barriers for interconversion of the atropisomers of selenoether $\mathbf{2} \mathbf{a}$ and telluroether $\mathbf{3 a}$, determined using either the coalescence of the chalcogen-Me or $o$-OMe signals, are very similar. This suggests that both coalescence phenomena are measuring the same process: rotation about the aryl-aryl bond.

It is surprising that only two signals are observed for the Me-X (X = chalcogen $)$ and $o$-methoxy groups in thioether $\mathbf{1 a}$, selenoether $\mathbf{2 a}$, and telluroether $\mathbf{3} \mathbf{a}$ because there are in fact three possible atropisomers: the anti isomer and two syn isomers ( $\boldsymbol{s y n}$ - $\boldsymbol{a}$ where the X-Me group is facing away from the methoxy groups; syn-s where the X-Me group is facing toward the methoxy groups); see Figure 10 where the three transition states for interconversion of the three atropisomers are also shown. The observation of only two signals for the O-Me and X-Me groups in the ${ }^{1} \mathrm{H}$ NMR spectra may be due to any of three reasons: (a) two of the signals in the three species have identical or nearly identical chemical shifts, (b) one of the conformers is present in amounts too small to be observed, or (c) some of the conformers interconvert rapidly on the NMR time scale, at the temperatures that are accessible in our experiments.

To decide which of the above three hypotheses is correct, we sought help from quantum chemical calculations. First we optimized the structures of all three atropisomers (and the four transition states between them) by the B3LYP/6-31G* method (see Figure 10). Thereby we found that conformer syn- $\boldsymbol{a}$ has a plane of symmetry for both $\mathrm{X}=\mathrm{S}$ and $\mathrm{X}=\mathrm{Se}$,
TABLE 5. Calculated ${ }^{1} \mathrm{H}$ NMR Spectroscopic Chemical Shifts for Me Groups in Thioether $1 \mathrm{a}^{a}$

\begin{tabular}{lccc}
\hline isomer & $\delta \mathrm{SMe}(\mathrm{ppm})$ & $\delta \mathrm{OMe}(1)(\mathrm{ppm})$ & $\delta \mathrm{OMe}(2)(\mathrm{ppm})$ \\
\hline $\boldsymbol{s y n}-\boldsymbol{a}, \mathrm{X}=\mathrm{S}$ & 1.56 & 3.69 & 3.69 \\
$\boldsymbol{s y n}-\boldsymbol{s}, \mathrm{X}=\mathrm{S}$ & 1.86 & 3.70 & 3.66 \\
anti, $\mathrm{X}=\mathrm{S}$ & 1.90 & 3.64 & 3.61
\end{tabular}

${ }^{a} \mathrm{GIAO} / \mathrm{WP} 04 / \mathrm{cc}-\mathrm{pVDZ}$ in DMSO as a continuum solvent, scaled using the optimized factors given in ref 21 .

but that $\boldsymbol{s y n}$-s lacks this symmetry element (the X-Me group is tilted toward one side and the dihedral angles to the two phenyl groups are not the same). The calculated structures are depicted in the Supporting Information along with their geometric coordinates.

Based on these geometries, the ${ }^{1} \mathrm{H}$ NMR chemical shifts for the S-Me and O-Me moieties in the atropisomers of thioether 1a (see Table 5) were calculated following the protocol outlined in ref 21 . The results of these calculations suggest that the chemical shifts for the SMe groups in the three conformers of thioether 1a should not overlap, although there may be overlap of the signals for the $\mathrm{OMe}$ groups. This excludes hypothesis (a), at least with regard to the $\mathrm{X}-\mathrm{Me}$ signals.

Next the relative enthalpies and free energies of the three conformers and the transition states between them were

(21) Jain, R.; Bally, T.; Rablen, P. R. J. Org. Chem. 2009, 74, 4017-4023. (22) Günther, H. NMR Spectroscopy, 2nd; Wiley: New York, 1992; 
TABLE 6. Relative Energies in $\mathrm{kJ} / \mathrm{mol}^{a}$ of Different Atropisomers of Thioether 1a and Selenoether 2a and Barriers for Their Interconversion (See Also Figure 10)

\begin{tabular}{|c|c|c|c|c|c|}
\hline \multirow[b]{2}{*}{ compound } & \multirow[b]{2}{*}{ conformer } & \multicolumn{2}{|c|}{ gas phase } & \multicolumn{2}{|c|}{ SCRF @DMSO } \\
\hline & & $H_{\text {rel }}$ & $G_{\text {rel }}$ & $H_{\text {rel }}$ & $G_{\text {rel }}$ \\
\hline \multirow[t]{7}{*}{$1 \mathrm{a}(\mathrm{X}=\mathrm{S})$} & syn-s & 1.03 & 2.04 & 1.26 & 2.27 \\
\hline & syn-a & (0) & (0) & $(0)$ & (0) \\
\hline & anti & 0.35 & 0.14 & 1.21 & 1.00 \\
\hline & $\mathrm{TS}(\boldsymbol{s y n}-\boldsymbol{a} \rightarrow \boldsymbol{s y n}-\boldsymbol{s})$ & 19.43 & 24.99 & 16.20 & 21.76 \\
\hline & $\mathrm{TS}($ anti $\rightarrow$ anti $)$ & 19.03 & 23.49 & 15.71 & 20.17 \\
\hline & $\mathrm{TS}(\boldsymbol{s y n}-\boldsymbol{s} \rightarrow \boldsymbol{a n t i})$ & 58.51 & 67.28 & 59.55 & 68.32 \\
\hline & $\mathrm{TS}(\boldsymbol{a n t i} \rightarrow \boldsymbol{s y n}-\boldsymbol{a})$ & 59.45 & 69.62 & 60.22 & 70.40 \\
\hline \multirow[t]{7}{*}{ 2a $(X=S e)$} & syn-s & 3.01 & 3.01 & 3.32 & 3.32 \\
\hline & syn-a & 0.00 & 0.00 & 0.00 & 0.00 \\
\hline & anti & 1.12 & 1.15 & 2.44 & 2.48 \\
\hline & $\mathrm{TS}(\boldsymbol{s y n}-\boldsymbol{a} \rightarrow \boldsymbol{s y n}-\boldsymbol{s})$ & 16.48 & 18.64 & 13.51 & 15.67 \\
\hline & $\mathrm{TS}(\boldsymbol{a n t i} \rightarrow \boldsymbol{a n t i})$ & 15.27 & 16.98 & 11.64 & 13.35 \\
\hline & $\mathrm{TS}(\boldsymbol{s y n}-\mathbf{s} \rightarrow \boldsymbol{a n t i})$ & 64.04 & 71.98 & 65.50 & 73.44 \\
\hline & $\mathrm{TS}(\boldsymbol{a n t i} \rightarrow \boldsymbol{s y n}-\boldsymbol{a})$ & 64.83 & 71.27 & 64.80 & 71.25 \\
\hline
\end{tabular}

${ }^{a}$ Calculated by the B2PLYP-D/cc-pVDZ//B2PLYP-D/cc-pVDZ method, using B3LYP/6-31G* thermal corrections and entropies.

calculated, using the recently introduced double hybrid B2PYLP method, corrected for dispersion energy contributions, in the gas phase and in DMSO as a continuum solvent (see Table 6). First we note that for $\mathrm{X}=\mathrm{S}$ the three conformers are within ca. $3 \mathrm{~kJ} / \mathrm{mol}$, i.e., one would expect all of them to be present in solution above room temperature (where $\mathrm{RT} \geq 2.5 \mathrm{~kJ} / \mathrm{mol}$ ). For $\mathrm{X}=\mathrm{Se}$ the situation is similar in DMSO (in the gas phase $\boldsymbol{s y n}$-s is more strongly disfavored). Thus, hypothesis (b) must also be discarded.

Finally, the barriers for interconverting the three atropisomers were examined (see Table 6). These calculations show that the barriers for rotation around the $\mathrm{Ph}-\mathrm{X}(\mathrm{Me})$ bond are too low to be detected by dynamic NMR in the temperature range that is accessible to us, both for $\mathrm{X}=\mathrm{S}$ and $\mathrm{X}=$ Se, i.e., that rapid equilibration between conformers $\boldsymbol{s y n}$ - $\boldsymbol{a}$ and $\boldsymbol{s y n}-\boldsymbol{s}$ is to be expected (and similar rotation in the anti conformer is also rapid on the NMR time scale). Interestingly these barriers decrease on going from $\mathrm{S}$ to Se, which can be understood easily because the increase of the $\mathrm{C}-\mathrm{X}$ bond length (by $0.14 \AA$ ) leads to a concomitant increase of the distance between the Me group that is attached to $\mathrm{X}$ and the $\mathrm{Ph}$ group that it encounters at the two transition states where this situation prevails (at a distance of $3.05 \AA$ of the methyl C atom perpendicular to the phenyl ring in both cases). On the other hand, the calculated barriers for converting the syn-a or syn-s to the anti conformers, i.e., for rotation of a lateral

(23) To quantitate this effect, we calculated the potential for the interaction of dimethylsulfide or dimethylselenide, respectively, with a benzene $\mathrm{H}$-atom as depicted. The equilibrium distance was $2.8 \AA$ for $\mathrm{S}$ and $3.0 \AA$ for Se. At the transition states for rotation around a lateral phenyl group in 1a the $\mathrm{S} \cdots \mathrm{H}$ distance is ca. $2.1 \mathrm{~A}$ and in $\mathbf{2 a}$ it is $2.3 \mathrm{~A}$. At these distances the energy is higher by $13.2 \mathrm{~kJ} / \mathrm{mol}$ in the model complex for $\mathrm{X}=\mathrm{S}$ and by $16.3 \mathrm{~kJ} / \mathrm{mol}$ for $\mathrm{X}=\mathrm{Se}$. The difference between these two numbers $(3.1 \mathrm{~kJ} / \mathrm{mol})$ accounts for a large part of the differences in the enthalpies of activation for rotation of a lateral phenyl group in $\mathbf{1 a}$ and $\mathbf{2} \mathbf{a}$.

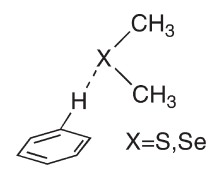

(24) House, H. O.; Hrabie, J. A.; VanDerveer, D. J. Org. Chem. 1986, 51, 921-929. phenyl group, are much higher and in good accord with the experimental free energies of activation reported in Table 4. In contrast to the low barriers discussed above, these barriers increase on going from $\mathrm{X}=\mathrm{S}$ to $\mathrm{X}=\mathrm{Se}$, in accord with experiment. The height of the barriers for rotation of a lateral phenyl group are dictated by the repulsion between the $o-\mathrm{H}$ atom of the phenyl ring and the central heteroatom. As the van der Waals radius of Se is larger than that of $\mathrm{S}$, that repulsion is larger and the barrier therefore higher for $\mathrm{Se}^{23}$

Thus it is to be assumed that the one of the X-Me resonances is the average of those for conformers $\boldsymbol{s} \boldsymbol{y} \boldsymbol{n}$ - $\boldsymbol{a}$ and $\boldsymbol{s y n}-\boldsymbol{s}$, while the other is that of the anti conformer. The same applies to the O-Me resonances, except in this case there is averaging between two resonances for the anti conformer.

Atropisomerism in the oxygen analogues of compounds 1-3 ( $m$-terphenyl ethers) has never been studied, but House and coworkers ${ }^{24}$ have measured the barrier for interconverting the syn and anti isomers of 1,8-diarylanthracenes $\mathbf{1 0}$. Surprisingly, they found that replacing the $\mathrm{OH}$ by an OAc group had little effect on that barrier. ${ }^{25,26}$ This was ascribed to splaying out of the 1,8-aryl groups that is evident in the $\mathrm{X}$-ray crystal structure of acetate $\mathbf{1 0 b} .^{24}$<smiles></smiles>

In conclusion, the effective syntheses and structural studies reported here and the electrochemical studies reported

(25) Interestingly, House et al. ${ }^{23}$ report a minor component in acetate $\mathbf{1 0 b}$ that rapidly interconverts with the syn isomer. They assign the structure of this minor component to the syn isomer with the OAc cis to the aryl methyl groups which equilibrates with the major syn isomer with the OAc trans to the aryl methyl groups. If this assignment for the minor component is correct, then the rotation barrier about the aryl-O bond in $\mathbf{1 0 b}$ is greater than the rotation barriers about the aryl-X bond $(\mathrm{X}=\mathrm{S}, \mathrm{Se}, \mathrm{Te})$ in the substituted and unsubstituted $m$-terphenyl chalcogenoethers $\mathbf{1}-\mathbf{3}$.

(26) (a) Lunazzi, L.; Mancinelli, M.; Mazzanti, A. J. Org. Chem. 2007, 72, 5391-5394. (b) Casarini, D.; Lunazzi, L.; Mazzanti, A. Eur. J. Org. Chem. 2010, 2035-2056.

(27) Lunazzi, L.; Mancinelli, M.; Mazzanti, A. J. Org. Chem. 2009, 74, $1345-1348$ report a high barrier $\left(\Delta G=38.0 \mathrm{kcal} / \mathrm{mol}\right.$ at $\left.140{ }^{\circ} \mathrm{C}\right)$ for racemization of chiral anthraquinone 11. The configurational stability of anthraquinone $\mathbf{1 1}$ was ascribed to steric interaction between the methylnaphthyl substituent and anthraquinone carbonyl group. However, this is only remotely related to the systems studied in the present paper.<smiles>Cc1ccc2ccccc2c1-c1cccc2c1C(=O)c1ccccc1C2=O</smiles>

11

(28) Still, W. C.; Kahn, M.; Mitra, A. J. Org. Chem. 1978, 43, 2923-2925. 
elsewhere suggest that unsubstituted and substituted $m$-terphenylthioethers $\mathbf{1}$ and selenoethers $\mathbf{2}$ may provide insight into through-space $\mathrm{S}$ and $\mathrm{Se} \cdot \pi \pi$ interaction. Consequently, studies are underway to elucidate the structure and bonding in their one-electron oxidation products.

\section{Experimental Section}

General. All reactions were performed using standard Schlenk techniques under an atmosphere of argon. THF was purified by distillation under $\mathrm{N}_{2}$ from potassium-benzophenone ketyl. Column chromatography was done using $32-63 \mu \mathrm{m}$ flash silica gel following the method of Still et al. ${ }^{28}$ Reactions were monitored by $\mathrm{GC}-\mathrm{MS}$ using a gas chromatograph with a ZB-5 ms column interfaced with a mass spectrometer. All $\mathrm{mp}$ are uncorrected. All ${ }^{1} \mathrm{H}$ variable-temperature, ${ }^{13} \mathrm{C}$, and APT NMR spectra were obtained using an NMR spectrometer operating at a ${ }^{1} \mathrm{H}$ frequency of $299.956 \mathrm{MHz}$, using a $5 \mathrm{~mm}$ Four-Nucleus probe. The ambient temperature without heating or cooling was $22-23{ }^{\circ} \mathrm{C}$. Carbon types $\left(\mathrm{CH}_{3} / \mathrm{CH}\right.$ or $\left.\mathrm{CH}_{2} / \mathrm{C}_{\mathrm{q}}\right)$ were determined from APT spectra. NMR chemical shifts and coupling patterns in the aromatic rings were elucidated by simulation and curve fitting using Win-DNMR version 7.1.12 (Reich, H. J., University of Wisconsin, Madison, WI). Low-temperature experiments used dry nitrogen gas-cooled to $77 \mathrm{~K}$ in a heat exchanger, and temperatures were calibrated using the ${ }^{1} \mathrm{H}$ shift separation of a low-volume methanol sample. All ${ }^{1} \mathrm{H}$ spectra are referenced to residual solvent at $\delta 2.49 \mathrm{ppm}\left(\mathrm{DMSO}-d_{6}\right)$ or $\delta 5.32 \mathrm{ppm}$ $\left(\mathrm{CD}_{2} \mathrm{Cl}_{2}\right)$, and all ${ }^{13} \mathrm{C}$ spectra are referenced to deuterated solvent at $\delta 39.51 \mathrm{ppm}\left(\mathrm{DMSO}-d_{6}\right)$ or $54.00\left(\mathrm{CD}_{2} \mathrm{Cl}_{2}\right) .{ }^{77} \mathrm{Se}$ NMR were acquired on a spectrometer operating at a ${ }^{77} \mathrm{Se}$ frequency of $95.2775 \mathrm{MHz}$ using a $5 \mathrm{~mm}$ broadband inverse 3-axis gradient probe at $25{ }^{\circ} \mathrm{C}$, with inverse-gated ${ }^{1} \mathrm{H}$ decoupling. All ${ }^{77} \mathrm{Se}$ spectra are referenced to external selenomethionine at $\delta 268.6 \mathrm{ppm}$. High resolution MS were obtained by direct insertion.

Synthesis of Thioether 1d from 2,6-Diphenylaniline 5. The procedure of Bryant et al. ${ }^{2}$ was adopted for the synthesis of thioether $1 \mathrm{~d}$. Isoamyl nitrite $(0.12 \mathrm{~mL}, 0.91 \mathrm{mmol})$ was added to a solution of 2,6-diphenylaniline $\mathbf{5}(83 \mathrm{mg}, 0.34 \mathrm{mmol})$ in dimethyl disulfide $(0.58 \mathrm{~mL})$ heated to $75^{\circ} \mathrm{C}$. After the addition, the temperature was raised to $90^{\circ} \mathrm{C}$ and held at this temperature for $2-3 \mathrm{~h}$. The solution was concentrated under reduced pressure and the residue chromatographed on preparative TLC plates eluting with hexanes to give thioether 1d (39 mg, 42\% yield): ${ }^{1} \mathrm{H} \mathrm{NMR}\left(\mathrm{CD}_{2} \mathrm{Cl}_{2}\right) \delta 1.664(\mathrm{~s}, 3 \mathrm{H}), 7.29(\mathrm{br} \mathrm{d}, J=7.4 \mathrm{~Hz}$, $2 \mathrm{H}), 7.33-7.53(\mathrm{~m}, 11 \mathrm{H}) ;{ }^{13} \mathrm{C}$ NMR $\left(\mathrm{CD}_{2} \mathrm{Cl}_{2}\right) \delta 19.45\left(\mathrm{CH}_{3}\right)$, $127.62(\mathrm{CH}), 127.98(\mathrm{CH}), 128.36(\mathrm{CH}), 130.12(\mathrm{CH}), 130.49$ $(\mathrm{CH}), 134.23\left(\mathrm{C}_{\mathrm{q}}\right), 142.72\left(\mathrm{C}_{\mathrm{q}}\right), 147.20\left(\mathrm{C}_{\mathrm{q}}\right) ; \mathrm{IR} v_{\max }(\mathrm{film}) / \mathrm{cm}^{-1}$ $3054(\mathrm{C}-\mathrm{H}), 2918(\mathrm{C}-\mathrm{H}), 2849(\mathrm{C}-\mathrm{H})$, MS (EI) $\mathrm{m} / z$ (rel intensity \%) $276\left(\mathrm{M}^{+}, 100\right), 261$ (64), 260 (35), 228 (10), 184 (19); HRMS (EI) calcd for $\mathrm{C}_{19} \mathrm{H}_{16} \mathrm{~S}$ : 276.0973, found 276.0966.

Synthesis of Thioether 1e by Suzuki Coupling with 2,6-Diiodo4-methylthioanisole 7. Following the procedure of Bryant et al., ${ }^{2}$ a solution of $\mathrm{Pd}\left(\mathrm{PPh}_{3}\right)_{4}(160 \mathrm{mg})$ and phenylboronic acid $(185$ $\mathrm{mg}, 1.52 \mathrm{mmol})$ in ethanol $(1 \mathrm{~mL})$ was added to a mixture of 2,6-diiodo-4-methylthioanisole ${ }^{2} 7(200 \mathrm{mg}, 0.512 \mathrm{mmol})$ in benzene $(3 \mathrm{~mL})$ and aqueous sodium carbonate $(1.28 \mathrm{~mL})$ at room temperature under a nitrogen atmosphere. The vigorously stirred mixture was heated at reflux for $7 \mathrm{~d}$ with the addition of more catalyst $(10-15 \%)$. The mixture was filtered, and the organic layer was separated, dried, concentrated, and column chromatographed on silica gel to give thioether $1 \mathrm{e}$ as a colorless solid (27\% yield): $\mathrm{mp} 86-87^{\circ} \mathrm{C} ;{ }^{1} \mathrm{H}$ NMR $\left(600 \mathrm{MHz}, \mathrm{CD}_{2} \mathrm{Cl}_{2}\right) \delta$ $1.666(\mathrm{~s}, 3 \mathrm{H}), 2.397$ (s, 3H), 7.147 (br s, 2H), $7.379(\mathrm{C}, 2 \mathrm{H}), 7.434$ $(\mathrm{B}, 4 \mathrm{H}), 7.495(\mathrm{~A}, 4 \mathrm{H})\left(\mathrm{AA}^{\prime} \mathrm{BB}^{\prime} \mathrm{C}, J_{\mathrm{ab}}=7.6, J_{\mathrm{bc}}=7.5, J_{\mathrm{aa}^{\prime}}=\right.$ $\left.1.5, J_{\mathrm{bb}^{\prime}}=1.9, J_{\mathrm{ac}}=1.3 \mathrm{~Hz}\right) ;{ }^{13} \mathrm{C} \mathrm{NMR}\left(150 \mathrm{MHz}, \mathrm{CD}_{2} \mathrm{Cl}_{2}\right) \delta$ $19.61\left(\mathrm{CH}_{3}\right), 21.27\left(\mathrm{CH}_{3}\right), 127.54(\mathrm{CH}), 128.30(\mathrm{CH}), 130.13$
$(\mathrm{CH}), 130.70\left(\mathrm{C}_{\mathrm{q}}\right), 131.34(\mathrm{CH}), 138.12\left(\mathrm{C}_{\mathrm{q}}\right), 142.86\left(\mathrm{C}_{\mathrm{q}}\right), 147.23$ $\left(\mathrm{C}_{\mathrm{q}}\right)$; IR $v_{\text {max }}(\mathrm{film}) / \mathrm{cm}^{-1} 3054(\mathrm{C}-\mathrm{H}), 2922(\mathrm{C}-\mathrm{H}), \mathrm{GC}-\mathrm{MS}$ $m / z 290\left(\mathbf{M}^{+}\right)$; HRMS (MALDI) calcd for $\mathrm{C}_{20} \mathrm{H}_{18} \mathrm{~S}: 290.11237$, found 290.11238 .

Synthesis of 1-3 via Grignard Reagent 9. The methodology used will be exemplified by the synthesis of thioether 1b. A solution of 2,6-dichlorophenyllithium was prepared following the procedure of Saednya and Hart. ${ }^{7}$ To a solution of 1,3-dichlorobenzene $8(1.47 \mathrm{~g}, 10 \mathrm{mmol})$ in dry THF $(25 \mathrm{~mL})$ under argon and cooled in a Dry ice-acetone bath was added a $1.6 \mathrm{M}$ solution of $n$-BuLi in hexanes $(10 \mathrm{mmol})$ dropwise by syringe over $20 \mathrm{~min}$. After stirring at this temperature for $1.5-2 \mathrm{~h}$, the resulting white slurry was rapidly added to a warmed solution of $m-\mathrm{MeOC}_{6} \mathrm{H}_{4}-\mathrm{MgBr}$, prepared by stirring a solution of $m$ - $\mathrm{MeOC}_{6} \mathrm{H}_{4} \mathrm{Br}(30 \mathrm{mmol})$ in dry THF $(30 \mathrm{~mL})$ with dried $\mathrm{Mg}$ turnings $(30-40 \mathrm{mmol})$ for $1 \mathrm{~h}$ at room temperature. A portion of this solution of Grignard $9, \mathrm{Ar}=m-\mathrm{MeOC}_{6} \mathrm{H}_{4}(27.5 \mathrm{~mL}, 5.00$ $\mathrm{mmol}$ ) was placed in a flask under argon and cooled in a Dry iceacetone bath. $S$-Methylthiosulfonate ${ }^{29}(0.94 \mathrm{~mL}, 1.26 \mathrm{~g}, 10 \mathrm{mmol})$ was added, and the reaction misture was stirred for $3 \mathrm{~h}$ with cooling. The mixture was allowed to warm to room temperature overnight. Water was added, and the mixture was extracted with $\mathrm{Et}_{2} \mathrm{O}$. After drying and evaporating, the solid was recrystallized from $\mathrm{CH}_{2} \mathrm{Cl}_{2}$ to give thioether $\mathbf{1 b}(2.48 \mathrm{~g}, 74 \%$ yield): $\mathrm{mp}$ $110-112{ }^{\circ} \mathrm{C} ;{ }^{1} \mathrm{H}$ NMR $\left(\mathrm{CD}_{2} \mathrm{Cl}_{2}\right) \delta 1.723(\mathrm{~s}, 3 \mathrm{H}, \mathrm{SMe}), 3.847$ (s, 6H, OMe), 6.925 (ddd, $J=8.3,2.7,0.9 \mathrm{~Hz}, 2 \mathrm{H}), 7.053$ (ddd, $\mathrm{J}=2.7,1.5,0.8 \mathrm{~Hz}, 2 \mathrm{H}), 7.07(\mathrm{ddd}, J=7.2,1.5,0.9 \mathrm{~Hz}, 2 \mathrm{H})$, $7.27-7.40(\mathrm{~m}, 5 \mathrm{H}) ;{ }^{13} \mathrm{C}$ NMR $\left(\mathrm{CD}_{2} \mathrm{Cl}_{2}\right) \delta 19.60\left(\mathrm{CH}_{3}\right), 55.81$ $\left(\mathrm{CH}_{3}\right), 113.08(\mathrm{CH}), 115.84(\mathrm{CH}), 122.52(\mathrm{CH}), 127.83(\mathrm{CH})$, $129.39(\mathrm{CH}), 130.43(\mathrm{CH}), 134.26\left(\mathrm{C}_{\mathrm{q}}\right), 144.04\left(\mathrm{C}_{\mathrm{q}}\right), 146.91\left(\mathrm{C}_{\mathrm{q}}\right)$, $159.78\left(\mathrm{C}_{\mathrm{q}}\right)$; IR $v_{\max }(\mathrm{KBr}) / \mathrm{cm}^{-1} 3047(\mathrm{C}-\mathrm{H}), 2997(\mathrm{C}-\mathrm{H})$, $2955(\mathrm{C}-\mathrm{H}), 2945(\mathrm{C}-\mathrm{H}), 2827(\mathrm{C}-\mathrm{H}), \mathrm{MS}$ (EI) $m / z$ (rel intensity \%) $336\left(\mathrm{M}^{+}, 100\right), 321$ (93), 306 (88), 247 (53), 234 (67), 202 (63); HRMS (EI) calcd for $\mathrm{C}_{21} \mathrm{H}_{20} \mathrm{O}_{2} \mathrm{~S}$ : 336.1184, found 336.1181 .

The other reactions reported in Table 1 were done in a similar way as that reported for thioether $\mathbf{1 b}$ except $\mathrm{Ph}_{2} \mathrm{~S}_{2}, \mathrm{Me}_{2} \mathrm{Se}_{2}$, $\mathrm{Ph}_{2} \mathrm{Se}_{2}, \mathrm{Me}_{2} \mathrm{Te}_{2}$, or $\mathrm{Ph}_{2} \mathrm{Te}_{2}$ were used instead of $S$-methyl thiosulfonate and the appropriate Grignard reagent used in place of $m$ - $\mathrm{MeOC}_{6} \mathrm{H}_{4} \mathrm{MgBr}$. The reactions were monitored by GC-MS after quenching with water and usually required column chromatography on silica gel for purification after completion of the reaction. Yields, physical properties, and spectroscopic details for $\mathbf{1 - 3}$ are found in the Supporting Information.

Synthesis of Selenoether $\mathbf{2 d}$ from $\mathbf{m}$-Terphenyliodide, $\mathbf{P h}_{2} \mathrm{Se}_{2}$, and $\mathbf{C s O H} \cdot \mathbf{H}_{2} \mathrm{O}$. The procedure used was adapted from that reported by Verala et al. ${ }^{16} \mathrm{~A}$ mixture of $m$-terphenyliodide (89 mg, $0.25 \mathrm{mmol}), \mathrm{Ph}_{2} \mathrm{Se}_{2}(117 \mathrm{mg}, 0.375 \mathrm{mmol}), \mathrm{CsOH} \cdot \mathrm{H}_{2} \mathrm{O}$ ( $84 \mathrm{mg}, 0.50 \mathrm{mmol})$, and DMSO $(0.75 \mathrm{~mL})$ was sealed in a Pyrex glass tube and placed in a sand bath maintained at $110^{\circ} \mathrm{C}$ for $24 \mathrm{~h}$. After cooling, the reaction mixture was added to crushed ice, and then aqueous $\mathrm{NH}_{4} \mathrm{Cl}$ solution was added. The mixture was stirred for 5-10 min and then repeatedly extracted with $\mathrm{Et}_{2} \mathrm{O}$. The combined extracts were dried $\left(\mathrm{MgSO}_{4}\right)$ and filtered. Silica gel was then added, and the mixture was concentrated under vacuum. The residue was put on a silica gel column and chromatographed to obtain $2 \mathbf{d}(55.6 \mathrm{mg}, 58 \%$ yield). The spectra (IR, ${ }^{1} \mathrm{H}$ and ${ }^{13} \mathrm{C}$ NMR) were the same as that prepared before and an intimate mixture with the compound prepared before showed an undepressed $\mathrm{mp}$.

The other reactions reported in Table 2 were conducted similarly but with the appropriate $m$-terphenyliodide and diphenyldichalcogenide.

Variable-Temperature NMR Studies. For temperatures above room temperature, DMSO- $d_{6}$ was used as the solvent, and for temperatures below room temperature, $\mathrm{CD}_{2} \mathrm{Cl}_{2}$ was used as the

\footnotetext{
(29) Scholz, D. Synthesis 1983, 944-945.
} 
solvent. The ${ }^{1} \mathrm{H}$ NMR exchange line fitting results were obtained using WinDNMR version 7.1.12 (Reich, H. J., University of Wisconsin, Madison, WI). The spectra used for fitting were acquired just below the coalescence temperature for the resonance being fitted in order to maximize the information content. Line widths were determined by fitting peaks well below the coalescence temperature where exchange broadening is negligible. Chemical shifts and relative peak areas of the two conformers, as well as the exchange rate constants were obtained by visual fit to the experimental data. The conformer present in greater concentration just below coalescence is referred to as the "A" conformer, and the other conformer is described as " $\mathrm{B}$ ". The free energy of activation was calculated using the equation ${ }^{22}$

$$
\Delta \mathrm{G}^{\ddagger}=[23.76-\ln (k / T)] R T
$$

Quantum Chemical Calculations. Geometry optimizations and frequency calculations were first done with the B3LYP/6-31G* method, where all stationary points (minima, transition states) were properly characterized. Geometries were then reoptimized with the recently introduced "double hybrid" B2PLYP functional, ${ }^{31 \mathrm{a}}$ corrected for contributions of dispersion energy, ${ }^{31 \mathrm{~b}}$ which accounts much better for steric interactions than pure DFT functionals. However, analytic second derivatives are not yet available for the B2PLYP method, so we had to use thermal corrections and entropies from B3LYP calculations in the evaluation of the relative enthalpies and free energies listed in Table 6. Finally, single-point SCRF calculations in DMSO as a continuum solvent were done with the B2PLYP-D functional at the corresponding geometries to evaluate relative enthalpies and free energies in solution. NMR chemical shifts were calculated

(30) Wiitala, K. W.; Hoye, T. R.; Cramer, C. J. J. Chem. Theory Comput 2006, 2, 1085-1092. In Gaussian, the WP04 functional is invoked by specifying the BLYP keyword and adding $\operatorname{iop}(3 / 76=1000001189,3 / 77=$ $0961409999,3 / 78=0000109999)$ to the keyword line. using the GIAO method and the WP04 functional that was developed with that purpose in mind ${ }^{30}$ using the cc-pVDZ basis set. SCRF calculations were again carried out in DMSO as a solvent, and the raw isotropic magnetic shieldings (IMS) were converted to chemical shifts relative to TMS $\delta$ by scaling them with the parameters elaborated recently by Jain et al. ${ }^{2 \mathrm{P}}(\delta=$ 31.844 - (IMS/1.0205)). All calculations were done with the Gaussian program packages. ${ }^{32}$

Acknowledgment. The authors gratefully acknowledge financial support of this work by the National Science Foundation (CHE-0455575, R.S.G., CHE-9610347) and the Swiss National Science Foundation (Project 2000-121747, T.B.). The authors also thank Mr. Takuhei Yamamoto for the preparation and characterization of thioether $\mathbf{1 e}$.

Supporting Information Available: Yields, physical properties and spectroscopic details for $\mathbf{1} \mathbf{- 3}$. Variable-temperature 300 $\mathrm{MHz}{ }^{1} \mathrm{H}$ NMR spectroscopic studies showing the full spectral range for thioether $\mathbf{1 a}$ in $\mathrm{CD}_{2} \mathrm{Cl}_{2}$ and DMSO- $d_{6}$, thioether $\mathbf{1 b}$ in $\mathrm{CD}_{2} \mathrm{Cl}_{2}$, thioether $\mathbf{1 h}$ in $\mathrm{CD}_{2} \mathrm{Cl}_{2}$ and DMSO- $d_{6}$, selenoether $\mathbf{2 a}$ in $\mathrm{CD}_{2} \mathrm{Cl}_{2}$ and DMSO- $d_{6}$, selenoether $2 \mathrm{e}$ in DMSO- $d_{6}$, telluroether 3a in $\mathrm{CD}_{2} \mathrm{Cl}_{2}$, and DMSO- $d_{6}$, telluroether $\mathbf{3 d}$ in DMSO- $d_{6}$. Fits of calculated and experimental NMR spectra for selenoether 2a and telluroether 3a. X-ray crystallographic data for thioether 1a in CIF format. Complete citation for the Gaussian Program. ${ }^{32}$ Calculated structures of the three atropisomers of thioether 1a and selenoether 2a. This material is available free of charge via the Internet at http://pubs.acs.org.

(31) (a) Grimme, S. J. Chem. Phys. 2006, 124, 034108/1-034108/16. (b) Schwabe, T.; Grimme, S. Phys. Chem. Chem. Phys. 2007, 9, 3397-3406. For an overview of these methods, see: Schwabe, T.; Grimme., S. Acc. Chem. Res. 2008, 41, 569-579.

(32) Frisch, M. J. et al. Gaussian 03, Revision E.01 and Gaussian 09, Revision A.02; Gaussian, Inc.: Wallingford, CT, 2003 (for complete reference, see Supporting Information). 